\title{
Obesidade: um problema para 0 ginecologista?
}

\author{
Edmund Chada Baracat \\ José Maria Soares Júnior
}

A obesidade afeta aproximadamente $40 \%$ da população adulta no Brasil, sendo estimada em 38,6 milhões pelo Instituto Brasileiro de Geografia e Estatística (IBGE) em conjunto com o Ministério da Saúde (2005). Constitui, pois, problema sério de saúde pública e o ginecologista deve participar no combate a esta morbidade.

O método mais empregado para avaliar a obesidade é o índice de massa corpórea (IMC), o qual servirá, também, para o controle da paciente durante o tratamento. Este cálculo é feito dividindo-se o peso em quilogramas (Kg) pelo quadrado da altura em metros $\left(\mathrm{m}^{2}\right)$. Considera-se obesa quando este índice for igual ou superior a 30 (WHO, 2000). Já mulheres com valores entre 25 e 30 são consideradas com sobrepeso, o que também pode se associar a repercussões negativas. Ademais, há outras formas de aferir a obesidade: prega cutânea, circunferência abdominal e ultra-sonografia ou ressonância nuclear magnética de partes moles (Soares Jr et al, 2005).

Deve-se salientar que a obesidade está relacionada com componentes genético, hereditário e comportamental. Este último representa um fator importante, visto que hábitos alimentares que resultam na ingestão de alimentos hipercalóricos e a ausência de atividade física contribuem em muito para o estabelecimento da obesidade. Por outro lado, indivíduos com antecedentes familiares de obesidade, que praticam esportes e têm dieta alimentar adequada conseguem manter o peso na faixa de normalidade.

Refere-se que essa afecção aumenta o risco de desenvolver niveis elevados de pressão arterial, diabete melito do tipo 2, doença cardíaca, acidente vascular encefálico, colelítiase e câncer da mama e do intestino grosso. Por esses motivos, a obesidade traz grande preocupação em termos de saúde (Soares Jr et al, 2005).

De acordo com Speroff e Fritz (2005), 60\% dos homens e mulheres obesos têm a síndrome metabólica. Esta, além de alto risco de diabete e doença cardiovascular, inclui três ou mais das seguintes características: hipertensão, hipertrigliceridemia, baixos niveis de HDL colesterol, obesidade abdominal e hiperglicemia.

$\mathrm{Na}$ transição menopausal e na pós-menopausa, há tendência de aumento do risco para obesidade e mudança da distribuição gordurosa corporal, que tende a prevalecer na região abdominal. As alterações da composição e da distribuição gordurosa corpórea nesta fase de vida da mulher estão relacionadas com a diminuição do estrogênio circulante e, também, com o aumento da relação androgênio/ estrogênio (Lovejoy, 2003; Speroff e Fritz, 2005). Contudo, há ainda controvérsias sobre essa hipótese. Hoje, acredita-se que a falta de exercícios físicos regulares e hábitos alimentares errôneos com a ingesta de alimentos hipercalóricos sejam também responsáveis pelo maior risco de obesidade (Sternfeld et al, 2004).

Em estudo epidemiológico com 676 mulheres que foram avaliadas antes da consulta ambulatorial de ginecologia, Fernandes et al (2005) verificaram a ocorrência de obesidade em aproximadamente 24\% das mulheres entrevistadas, das quais $64 \%$ se concentravam nas faixas etárias entre 40 e 59 anos. Deve-se ressaltar que muitas delas encontravam-se no período de transição menopausal e na pós-menopausa. Assim, o ginecologista deve se preocupar com as repercussões negativas da obesidade durante esta fase da vida.

Outro ponto importante deste estudo é que a prevalência de sobrepeso e obesidade foi alta em mulheres com baixo nível socioeconômico e baixa escolaridade (Fernandes et al, 2005). Assim, a falta de informações sobre atividade física adequada e para aquisição de alimentos mais saudáveis e menos calóricos constituem importantes fatores a serem enfrentados pelas nossas pacientes.

Estes dados reforçam a necessidade de politicas de atenção a saúde envolvendo o combate à obesidade, em especial, em mulheres na transição menopausal e na pós-menopausa. O ginecologista deve participar deste processo, orientando as pacientes sobre dieta alimentar balanceada e incentivando a prática de esportes ou atividade física regular. Em alguns casos especiais, pode ser recomendada o terapia farmacológica. Deve-se ainda salientar que a psicoterapia é fundamental para o sucesso de tratamento.

\section{Referências Bibliográficas:}

1. Fernandes AMS, Leme LCP, Yamada EM et al. Avaliação do índice de massa corpórea em mulheres atendiadas em ambulatório geral de ginecologia. Rev Bras Ginecol Obstet. 2005; 27(2):69-74.

2. Instituto Brasileiro de Geografia e Estatística (IBGE) http://www.ibge.gov.br/english/presidencia/noticias/ noticia visualiza.php?id noticia $=278$ \&id pagina $=1$. Acesso 30 de abril de 2005.

3. Lovejoy JC. The menopause and obesity. Prim Care. 2003;30(2):317-25.

4. Soares Jr JM, Espósito IC, Patriarca MT, Baracat EC. Obesidade. In: Guias de Medicina Ambulatorial e Hospitalar UNIFESP/Escola Paulista de Medicina. Baracat EC e Rodrigues de Lima G (eds). Manole, São Paulo, 2005: 385-394.

5. Speroff L, Fritz MA. Obesity. The physiology of adipose tissue, and the problem of obesity. In: Clinical Gynecologic Endocrinology and Infertility. Speroff L e Fritz MA (eds). Lippincott Williams \& Wilkins. Philadelphia, 2005: 779-804.

6. Sternfeld B, Wang H, Quesenberry CP Jr et al. Physical activity and changes in weight and waist circumference in midlife women: findings from the Study of Women's Health Across the Nation. Am J Epidemiol. 2004;160(9):912-22.

7. WHO (2000) Obesity: Preventing and Managing the Global Epidemic: Report of a WHO Consultation on Obesity. 